\title{
ARCHITECTURAL DIVERSITY IN ANTARCTICA AND ITS HISTORICAL CORRELATION
}

\author{
Cristina Engel de Alvarez*, Marina Silva Tomé \& Paulo Sergio de Paula Vargas \\ LPP/UFES - Laboratório de Planejamento e Projetos da Universidade Federal do Espírito Santo. \\ Av. Fernando Ferrari n514, CEMUNI I sala 7. Vitória, ES - Brasil. CEP 29075-910. \\ *e-mail: cristina.engel@ufes.br \\ https://doi.org/10.4322/apa.2016.018
}

\begin{abstract}
The first contact of man with Antarctica occurred through reconnaissance expeditions and/or fishing activities, with increasing investments over time from various countries and motivated by scientific, economic and strategic interests. While the first buildings constructed in Antarctica were usually used for short periods of permanence and had reduced comfort, the increased interest in the continent associated to new technologies has resulted in major improvements in the quality of housings. This advancement raised questions related to the new constructions: the concern with the environment and the consequences of the presence of man in the region. The aim of this research was to describe the architectural production in different periods and classify these buildings according to their specific characteristics. Because the present work is a research typically based on literature, the methodology used sought to investigate documents, books, articles and journals and, additionally, to obtain information from the various reference Antarctic Programs. Importantly, the analysis of what is built in Antarctica represents also an assessment of the socio-political context of Nations that occupy the continent. As a result, buildings were classified according to the construction period and were inserted in the context of the division into historical, environmental and technological times.
\end{abstract}

Keywords: Historical Times, Scientific Stations, Antarctic Architecture, Wooden Construction.

\section{Introduction}

According to Friend (2009), the Antarctic continent has been the stage of human occupation for more than one century and is considered the land of superlatives because it is the most remote, more desert, windiest, more sterile, with highest average surface and the most uninhabitable region of the planet. Despite this, over the years, man has been trying to settle there, overcoming the precarious early shelters through the advancement and use of technology. The limitations to human actions and the environmental care imposed by the Madrid Protocol (Ministério do Meio Ambiente, 1995) involved new principles for construction and operation of research stations in the Antarctic continent.

Considering the context of the history of occupation of Antarctica, the purpose of this research was to characterize the architectural production throughout the different periods and classify it according to their specificities.

\section{Materials and Methods}

In the research, we aimed to identify the historical and cultural context of the country of origin and the general situation of the buildings in the entire building history of Antarctica. To this end, a literature review and research were conducted in the main bibliographies available on the subject and in the most relevant Antarctic Programs, in view of the need to obtain essential information for characterization of the architecture present in the continent.

\section{Results}

Within the context of human occupation in Antarctica, Alvarez (1995) presents three distinct periods: historical time, technological time and environmental time. This division can be perceived in the differences observed in the buildings, representing the main concerns of the moment to which they refer. 
The historical period dates back to the time of identification of the economic potential and territory reclamation. The technological time was marked by interest in the continent, driven by the International Geophysical Year and the establishment of the Antarctic Treaty. Finally, the environmental time was a period characterized by concern with reduction of environmental impacts caused by human occupation.

\section{Discussion and Conclusion}

The first buildings designed in the late 19th century basically had the function of serving as fishing support buildings and, mainly, as support structures for expeditions, usually led by European explorers whose purpose was to recognize an area still little known to man (Alvarez, 1995). In most cases, those buildings were temporary occupations

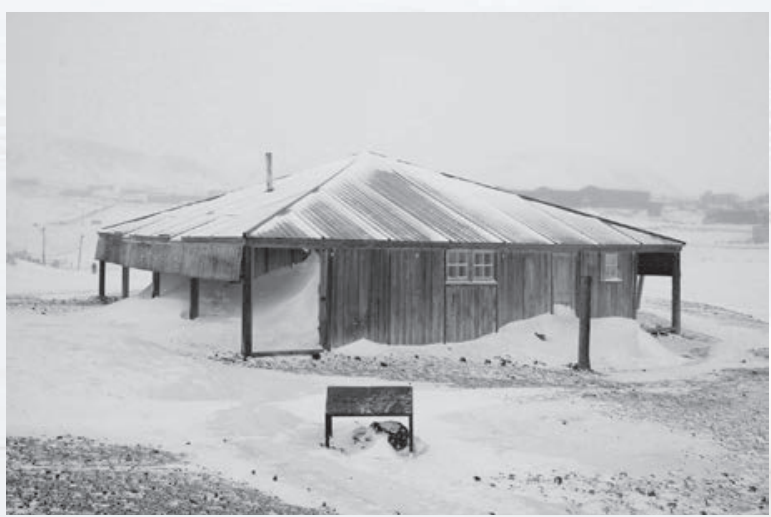

Figure 1. Robert F. Scott's Cabin.

Source: American Geopysical Union, 2010

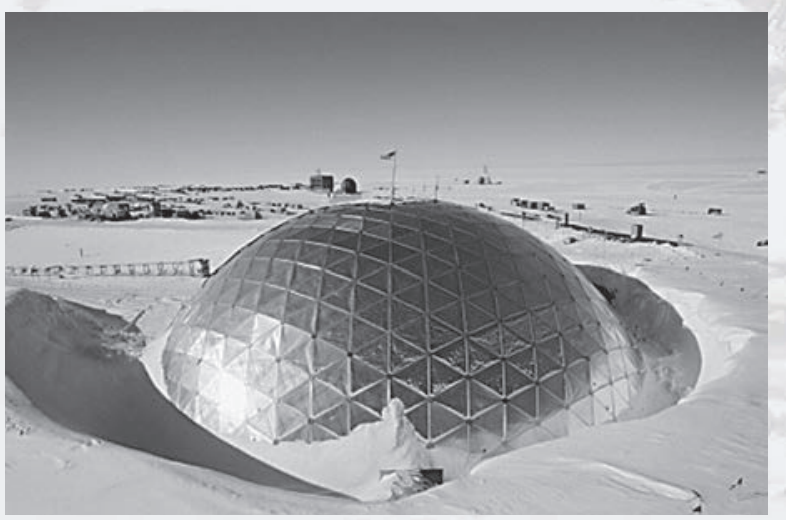

Figure 2. The former dome of the Amundsen-Scott Station. Source: ArticPhoto, 2013 located by the coast, and they would serve expeditions or fishing activity for a short time in precarious conditions of comfort and safety. This first period, named "historical times", refers to an era in which histories and stories of bravery, heroism and sacrifice proliferated (Palinkas \& Suedfeld, 2008).

In the architectural context, the lack of knowledge on the conditions present in the region resulted in architecture marked by experimentation. At first, the material chosen for building was wood because this was already fairly used in similar situations or because it was commonly used in the country of origin of the buildings. When used in fencing systems, wood provided acceptable levels of comfort and made it possible to ensure human survival, mainly in the periods of Antarctic summer. Its use has made possible the use of prefabricated components in buildings, a fundamental feature when considering the lack of logistic support in the ground.

An example of a building from the architectural period is the cabin designed by Robert Falcon Scott (Figure 1) as part of the strategic logistical plan of conquest of South Polo that took place in 1911.The building, which has its main components made of wood, was manufactured in England and assembled in Antarctica and is now considered architectural heritage of mankind (Friend, 2009). The good condition of the cabin is noteworthy, with its main original wooden elements fully preserved despite exposition to aggressive conditions.

Later, from the 1950s onwards, the period called "technological times" started (Mocellin et al., 1982). A highly favorable international atmosphere to the occupation of the territory was gradually established by the increased interest of many nations on the continent driven by the International Geophysical Year in 1958, the institution of the Antarctic Treaty in 1959, and by evidence of the existence of natural resources in high abundance.

Furthermore, the technological and industrial development of that time gave way for the creation of new types of buildings and a more systematic and permanent occupation, which was an important breakthrough to the scientific research developed in the continent. Buildings with more complex programs and with the best technology of that time were produced, with large use of appealing material, particularly steel (IAB, 2012). 
The use of these technologies for construction made it possible to meet new needs related to thermal isolation, ease by monad vantage and transportation, more efficiently. Building designs began to take into account even fire resistance, structural safety and logistic feasibility at the lowest cost.

Among the various buildings of this period, the Amundsen-Scott station (Figure 2) stands out, which was built to support researchers during the International Geophysical Year and had its construction completed by February 1957 (National Science Foundation, 2013). Its location represented a milestone for human occupation of the continent, and its construction employed different techniques to overcome the difficulties imposed by the environment.

With respect to building techniques and expansion of security and comfort in the buildings, attention turned to the need for reduction of environmental impacts caused by human occupation of the continent.

At the same time, the Madrid Protocol (Ministério do Meio Ambiente, 1995) stipulated restrictions to the human presence in the continent and promoted a discussion about environmental responsibility. From then on, all signatory countries of the Antarctic Treaty have to attend environmental requirements in order to keep their facilities in the continent. This is the so-called "environmental times", when the focus goes beyond constructive solutions aiming at higher suitability to adversities, and now includes also the concern for better adaptation of buildings to the Environment (IAB, 2012).

New aspects of the process of manufacture and assembly to operation and maintenance began to influence the solutions employed, for example, in the constructive system, materials, energy generation and treatment of waste. Thus, a great diversity of architectural solutions appeared for what, generally, is the same problem: building in Antarctica.

Over the years, the increased interest in the continent and environmental concerns have encouraged countries to seek solutions increasingly creative and innovative in the architecture. As examples of this diversity of solutions, the station Princess Elisabeth Antarctica station, from Belgium

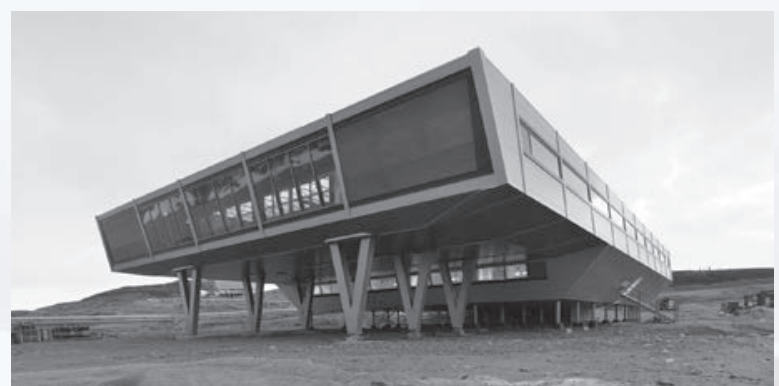

Figure 3. Princess Elisabeth Antarctic station. Source: Berle, 2013.

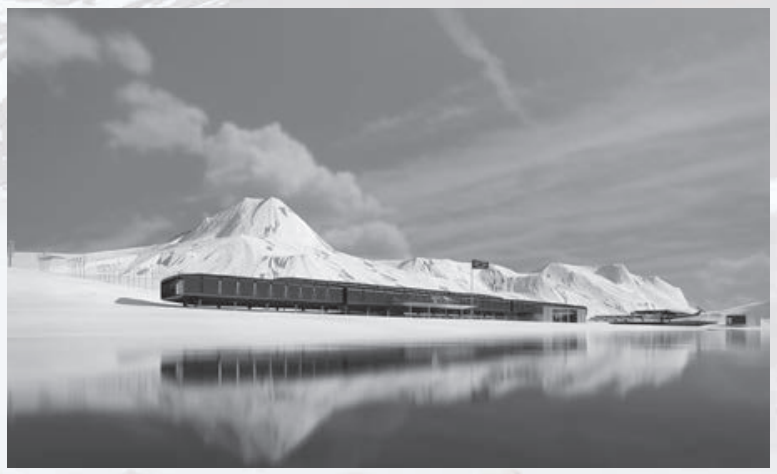

Figure 4. Architectural design contest winner for the reconstruction of Comandante Ferraz Antarctic Station.

Source: Concursos de projeto/web magazine.

(Figure 3), and the project for the new Comandante Ferraz Antarctic Station, Brazil (Figure 4), can be cited.

\section{Acknowledgements}

This work is part of the National Institute of Science and Technology Antarctic Environmental Research (INCT-APA) that receives scientific and financial support from the National Council for Research and Development (CNPq process: $\mathrm{n}^{\circ} 574018 / 2008-5$ ) and from the Carlos Chagas Research Support Foundation of the State of Rio de Janeiro (FAPERJ $n^{\circ}$ E-16/170.023/2008). The authors also acknowledge the support of the Brazilian Ministry of Science, Technology and Innovation (MCTI), Ministry of Environment (MMA) and Inter-Ministry Commission for Sea Resources (CIRM). 


\section{References}

Alvarez, C. E. Arquitetura na Antártica: ênfase nas edificações brasileiras em madeira. (Dissertação de mestrado em arquitetura e urbanismo). Universidade de São Paulo, 1995.

American Geopysical Union - AGU. (2010). Places of reverence: frozen in time. Retrieved in 20 August 2013, from http:// blogs.agu.org/wildwildscience/2010/03/19/places-of-reverence-frozen-in-time/

Concursos de Projeto. (2013). Estação Antártica Comandante Ferraz - $1^{\circ}$ /ugar. Retrieved in 21 August 2013, from http:// concursosdeprojeto.org/2013/04/17/estacao-antartica-comandante-ferraz-1o-lugar/

Friend, S. H. Sustainability and habitation in Antarctica. (Dissertação de mestrado). Montana: Montana State University, 2009.

Instituto dos Arquitetos do Brasil - IAB. (2012). Termo de Referência: Anexo 1 do concurso da Estação Antártica Comandante Ferraz. Retrieved in 25 April 2013, from http://concursoestacaoantartica.iab.org.br/bases/TERMO_DE_REFERENCIA_EACF. pdf

Brasil. Ministério do Meio Ambiente. Secretaria de Biodiversidade e Florestas. (1995). Protocolo ao Tratado da Antártida sobre proteção do Meio Ambiente (Protocolo de Madri). Brasília.

Mocellin, J. S. P., Villela, R. J., \& Ribas, F. C., Jr. (1982). Antártida: o sexto continente. [S.I.]: Olivetti do Brasil. 77p.

National Science Foundation - NSF. (2013). Amundsen-Scott South Pole Station. Retrieved in 20 August 2013, from http:// www.nsf.gov/geo/plr/support/southp.jsp

Palinkas, L. A., \& Suedfeld, P. (2008). Psychological effects of polar expeditions. The Lancelet, 371(9607), 153-163. 